\title{
DEVELOPMENT AND STABILITY OF SOME SUDANESE SUNFLOWER HYBRIDS UNDER IRRIGATED CONDITIONS
}

\author{
Mohamed, M.Y.
}

Oilseed Crops Research Center, Agricultural Research Corporation (ARC), P.O. Box 126, Wad Medani, Sudan

Received: March 18, 2010

Accepted: May 28, 2010

\section{SUMMARY}

Sunflower (Helianthus annuus L.) is a new edible oil crop in Sudan. Many production constraints are responsible for fluctuation in its production and productivity. The main constraint is a lack of adapted, improved, highyield sunflower varieties. Farmers depend on imported seeds, which are usually unavailable and expensive. To reduce the cost of the seed and ensure seed supply at the optimum time, ten single-cross sunflower hybrids (SFH32, SFH36, SFH37, SFH310, SFH313, SFH314, SFH341, SFH345, SFH302 and SFH325) and the hybrid Hysun-33 (the check) were evaluated for yield potential and yield components. The experiment was laid-out in a randomized complete block design with three replications carried over five irrigated locations during the winter season of 2008/2009. There was considerable variation for yield and its components among the hybrids and locations. Significant differences were observed for hybrids (G), locations (E) and $\mathrm{G} \times \mathrm{E}$ interaction. All the genotypes gave high seed and oil yields under irrigated conditions. Three hybrids, SFH310, SFH313 and SFH341, performed better than Hysun-33 and the other genotypes across five environments. Stability analysis identified SFH310, SFH313 and SFH341 as the most stable hybrids for seed and oil yields, since their regression coefficients were close to the value of one $\left(b_{i}=1\right)$ and had the lowest deviation from regression $\left(\mathrm{S}^{-2}{ }_{\mathrm{di}}\right)$. In contrast, hybrids such as SFH32 and SFH37, with regression coefficients greater than one, were regarded as sensitive to environmental changes for seed and oil yields. The three promising hybrids were released last June for commercial production.

\section{Key words: sunflower, Helianthus annuus, $\mathrm{G} \times \mathrm{E}$ interaction, stability parameters}

\section{INTRODUCTION}

Sunflower (Helianthus annuus L.) is an annual that is the source of one of the most important edible oils on a global scale. There is an increasing interest in sun-

* Corresponding author: e-mail: wadyounis@hotmail.com 
flower production worldwide due to the crop's adaptability and high oil quality (Škorić, 1992). In Sudan, oilseed crops rank second after cereals in area and total production. The country's oilseed production rests mainly on sesame (Sesame indicum L.), groundnut (Arachis hypogaea L.), and cotton seed (Gossypium hirsutum L.), while sunflower has been introduced recently into the cropping sequence.

Sunflower is a promising oilseed in Sudan. The seeds of sunflower have a high oil content $(40-50 \%)$ and are $30 \%$ digestible protein and can thus be used as a source of food for humans or as a poultry feed. Sunflower cake can also be used as animal feed. Sunflower is adaptable to a wide range of climatic conditions and is well suited for Sudanese conditions too. It can be a suitable winter oil crop in irrigated conditions. Sunflower seeds, which are a raw material for the oil industry, can increase the capacity of the local crushers, and the extra raw material can be exported to the Arab countries.

Extensive commercial production of sunflower was initiated in Sudan in the late 1980's and the early 1990's with the introduction of hybrids such as Hysun-33 from Australia and PAN-7351 from South Africa (El Ahamdi, 2003; Nour et al., 2005). The production was established mainly in rainfed areas of the country and, to a lesser extent, in irrigated conditions. At about the same time, early maturing accessions of two open-pollinated sunflower varieties, Rodio and Bolereo, were released under the names Damazin-1 and Damazin-2, respectively (Adam and Osman, 1989). In the two decades since then, nevertheless, sunflower has failed to expand significantly in the country in total area and seed production, which could be attributed mainly to production constraints.

There are many production constraints that are responsible for the fluctuation in area and productivity. These include frequent dry spells, erratic distribution of rainfall, lack of advanced technologies such as hybrid seeds, poor cultural practices, problems with empty seeds, low use of fertilizers, and faulty policies on funding, processing and marketing. Still, the lack of improved sunflower hybrids developed locally has emerged as the main limiting factor. Sunflower hybrid seeds are introduced from abroad and are bought with hard currency at a price that farmers can hardly afford. There is also the problem of hybrid seeds not being available at optimum planting time.

Sunflower, a cross-pollinated crop, provides an opportunity for developing new and superior hybrids through the use of breeding for heterosis. The practical use of heterosis in sunflower became possible after a source of cytoplasmic male sterility was identified by Leclercq (1966) in France and fertility restoration was discovered in the U.S. (Kinman, 1970). Development of the first sunflower hybrid based on cytoplasmic male sterility in the early 1970's intensified the interest of farmers in growing this crop (Miller, 1999). In Sudan, the value of hybrids and importance of heterosis breeding in sunflower were not sufficiently recognized. Nevertheless, our breeding program is now dealing mainly in the development of new single-cross hybrids characterized by uniform plant height, flowering date and seed quality. In 
addition, the hybrids are more stable, highly responsive to high-input agriculture, and highly self-fertile, resulting in higher seed set in areas where pollinators are not abundant. Thus, the development of sunflower hybrids for Sudanese conditions is an important step towards narrowing down the gap between supply and demand in the seed market and boosting sunflower production and productivity in the country. This will also cut down the time and resources being spent on importations from abroad. Sunflower hybrid seed produced locally is likely to be adopted by the majority of sunflower growers, since the seed source is readily available.

On the other hand, in a plant breeding program, potential genotypes are usually evaluated in different environments before selecting desirable ones that show stability across environments. Also, in identifying such genotypes, $\mathrm{G} \times \mathrm{E}$ interactions are of major concern for the breeder, because such interactions confound the selection of superior cultivars by altering their relative productiveness in different environments. Use of stability is a good technique for measuring the adaptability of different crop varieties to varying environments. The most widely used way to biometrically assess stability is the regression method, which is based on regression of the mean value of each genotype on the environmental index. The technique to measure stability was previously proposed by Finlay and Wilkinson (1963) and was later improved by Eberhart and Russell (1966). The stability of a variety or hybrid was defined by a high mean yield and regression coefficient $\left(b_{i}=1\right)$ and deviations from regression as small as possible $\left(\mathrm{S}_{\mathrm{di}}^{2}=0\right)$.

The objectives of the present study were to:

1. determine the yield performance and stability of ten local sunflower hybrids across five environments, and

2. select the best hybrid(s) for irrigated conditions in Sudan.

\section{MATERIALS AND METHODS}

\section{Development of single-cross sunflower hybrids}

The development of single-cross sunflower hybrids involves the crossing of a cytoplasmic male sterile line as the female parent (A-line) to a fertility restorer line as the male parent (R-line). The initial breeding material of cytoplasmically male sterile lines and their counterparts was introduced from France during the 2002/ 2003 season. The full-sib progeny method was used in both the female and maintainer lines (B-lines) for monitoring purity from pollen shedders and branching types. Plants selected as pairs of A and B-lines were characterized by uniformity in height, flowering period, and the same emergence date. Plants with defects like lodging, being an off-type, branching, poor pollen shedding, and susceptibility to diseases were discarded. The selected lines were crossed together to increase the seed of A-lines. The female parents (A-lines) and their maintainers (B-lines) were maintained during the 2002-2005 period. The male parents (R-line) or restorer lines were developed from finished $\mathrm{F}_{1}$ hybrids introduced from other countries. For this purpose, the $F_{1}$ hybrids were selfed for six or seven generations alternately by sib-pollination after segregation in later generations. Therefore, self-pollination, sib- 
pollination and selection were carried out within and among progeny rows in later segregating populations. The segregating populations for fertile plants and branching type in each $\mathrm{F}_{1}$ hybrid were considered for selecting the male parents (R-lines). For three seasons, $(2005,2006$, and 2007), forty to fifty single-cross hybrids in addition to Hysun-33 (as the check) were evaluated in preliminary yield trials. Based on the performance and seed yield, ten hybrids were produced from one Aline (SA3) and ten R-lines (SR2, SR6, SR7, SR10, SR13, SR14, SR41, SR45, SR02, and SR25Br) were selected for further testing at different sites (Table 1). The ten local Sudanese sunflower hybrids designated as SFH32, SFH36, SFH37, SFH310, SFH313, SFH314, SFH341, SFH345, SFH302, and SFH325 were evaluated against Hysun-33 at Sennar, Wad Medani, Rahad, New Halfa and Suki (Table 2).

Table 1: Line, pedigree, origin and hybrid designation of the tested material

\begin{tabular}{|c|c|c|c|}
\hline Line & Pedigree & Origin & Hybrid \\
\hline SA3 \& SB3 & $\mathrm{A}$ and $\mathrm{B}$-line developed from line $\mathrm{H} 52$ & France & \\
\hline SR 2 & Segregating population from restorer line RHA274 & France & SFH 32 \\
\hline SR 6 & Segregating population from $\mathrm{F}_{1}$-hybrid Velja & Serbia & SFH 36 \\
\hline SR 7 & Segregating population from $\mathrm{F}_{1}$-hybrid NS-H-712 & Serbia & SFH 37 \\
\hline SR 10 & Segregating population from $F_{1}$-hybrid PAN-7392 & South Africa & SFH 310 \\
\hline SR 13 & Segregating population from $F_{1}$-hybrid PAN-7355 & South Africa & SFH 313 \\
\hline SR 14 & Segregating population from $F_{1}$-hybrid IRNA & France & SFH 314 \\
\hline SR 41 & Segregating population from $F_{1}$-hybrid HS-2239 & Romania & SFH 341 \\
\hline SR 45 & Segregating population from $\mathrm{F}_{1}$-hybrid NS-H-111 & Serbia & SFH 345 \\
\hline SR 02 & Segregating population from restorer line RHA274 & Turkey & SFH 302 \\
\hline SR 25 & Segregating population from restorer line RHA274 & France & SFH 325 \\
\hline
\end{tabular}

Table 2: Locations and soil properties under which sunflower hybrids were evaluated

\begin{tabular}{lccccc}
\hline Location & Sennar & Medani & Rahad & Halfa & Suki \\
\hline Envr. No. & $\mathrm{E} 1$ & $\mathrm{E} 2$ & $\mathrm{E} 3$ & $\mathrm{E} 4$ & $\mathrm{E} 5$ \\
Latitude & $13^{\circ} 33^{\prime} \mathrm{N}$ & $14^{\circ} 23^{\prime} \mathrm{N}$ & $13^{\circ} 28^{\prime} \mathrm{N}$ & $15^{\circ} 19^{\prime} \mathrm{N}$ & $13^{\circ} 25^{\prime} \mathrm{N}$ \\
Longitude & $33^{\circ} 34^{\prime} \mathrm{E}$ & $33^{\circ} 29^{\prime} \mathrm{E}$ & $33^{\circ} 31^{\prime} \mathrm{E}$ & $35^{\circ} 36^{\prime} \mathrm{E}$ & $33^{\circ} 51^{\prime} \mathrm{E}$ \\
Altitude (m a.s.I.) & 416 & 405 & 421 & 450 & 430 \\
Clay content \% & 58 & 54 & 60 & 65 & 68 \\
pH & 8.2 & 8.0 & 8.1 & 7.9 & 7.8 \\
Available P mg kg ${ }^{-1}$ & 2.8 & 3.0 & 1.8 & 2.0 & 3.0 \\
O.C \% & 0.50 & 0.36 & 0.60 & 0.40 & 0.60 \\
$\mathrm{~N} \%$ & 0.05 & 0.03 & 0.05 & 0.03 & 0.03 \\
\hline
\end{tabular}

Source: Soil Survey Department, ARC-Sudan

\section{Experimental design and procedure}

In each environment, sunflower hybrids were arranged in a randomized complete block design with three replications. The plots had 4 rows $6 \mathrm{~m}$ long spaced $0.80 \mathrm{~m}$ apart. Seeds were sown in hills spaced $0.30 \mathrm{~m}$ apart within ridges and thinned to one plant per hill two weeks after planting. Sowing was done during the 
second week of November in the winter of 2008. Nitrogen was applied at $80 \mathrm{~kg}$ urea per hectare. Irrigation was applied at intervals of 12-14 days depending on weather conditions. Hand weeding was carried out to keep the crop weed free. The harvest was done during the first and second week of March, 2009. Manual labor was used for planting and threshing and all recommended agronomic practices were followed throughout the season. Data were collected for seed $\left(\mathrm{kg} \mathrm{ha}^{-1}\right)$ and oil yields. Over all environments, diseases were not identified, but frequent occurrences of wilt diseases, powdery mildew and leaf spots were observed during the Kharif season. The most important pests were birds, which attacked the crop at seed development and maturity during the winter season, especially at Rahad.

The data were subjected to separate and combined analysis of variance assuming random environment and fixed hybrid according to a procedure described by Gomez and Gomez (1984). Stability analysis of seed and oil yields were made following the model of Eberhart and Russell (1966) using a computer program written in BASIC.

\section{RESULTS AND DISCUSSION}

The pooled analysis of variance for seed and oil yields showed highly significant differences ( $p>0.01)$ among the hybrids (G) and environments (E) (Table 3).

Table 3: Pooled analysis of variance of seed and yields $\left(\mathrm{kg} \mathrm{ha}^{-1}\right)$ in 11 sunflower hybrids evaluated in five locations

\begin{tabular}{llcc}
\hline Source of variation & d.f & Mean squares for seed yield & Mean squares for oil yield \\
\hline Environment $(E)$ & 4 & $10640923.7^{* \star}$ & $2482023.2^{\star \star}$ \\
Hybrid $(G)$ & 10 & $320483 .^{\star \star}$ & $79853.8^{\star \star}$ \\
$G \times E$ interaction & 40 & $122816 .^{* *}$ & $27425.7^{\star \star}$ \\
Error & 100 & 62232.73 & 10853.77 \\
\hline
\end{tabular}

** significant at 0.01 probability level

Table 4: Analysis of variance for stability for seed and oil yields in sunflower hybrids across five environments

\begin{tabular}{llcc}
\hline Source of variation & d.f & MS. seed yield $\left(\mathrm{kg} \mathrm{ha}^{-1}\right)$ & MS. oil yield $\left(\mathrm{kg} \mathrm{ha}^{-1}\right)$ \\
\hline Hybrid $(\mathrm{G})$ & 10 & $106827.2^{\star \star}$ & $26618.2^{\star \star}$ \\
Environment $(\mathrm{E})$ & 4 & $3546980.0^{\star \star}$ & $827343.5^{\star \star}$ \\
$\mathrm{G} \times \mathrm{E}$ & 40 & $40938.0^{\star \star}$ & $9141.65^{\star \star}$ \\
$\mathrm{E}=(\mathrm{G} \times \mathrm{E})$ & 44 & $359669.09^{\star \star}$ & $83523.63^{\star \star}$ \\
$\mathrm{E}$ (Linear) & 1 & $14187899.0^{\star \star}$ & $3309364.8^{\star \star}$ \\
$\mathrm{G} \times \mathrm{E}$ (Linear) & 10 & $56999.6^{\star}$ & $9895.88^{\star}$ \\
Pooled deviation & 33 & $32350.18^{\star}$ & $8082.32^{\star \star}$ \\
Pooled error & 100 & 62232.52 & 10851.71 \\
\hline
\end{tabular}

These differences indicate the presence of potential genetic variability for seed yield and its components under study. The hybrid $\times$ environment $(G \times E)$ interac- 
tion was also highly significant for seed and oil yields. This shows that hybrids react differently in different environments for seed and oil yields, so the $(G \times E)$ interaction was further partitioned into linear and non-linear (pooled deviation) components (Table 4). Mean squares for both components were highly significant, indicating that both predictable and un-predictable components shared the $\mathrm{G} \times \mathrm{E}$ interaction. The $\mathrm{G} \times \mathrm{E}$ (linear) interaction was highly significant when tested against pooled deviation, which revealed that there are genetic differences among the hybrids for their regression on the environmental index. Thus, the presence of a highly significant $\mathrm{G} \times \mathrm{E}$ interaction for seed and oil yields in the present study necessitated the identification of the most stable and high-yielding hybrids using the Eberhart and Russell (1966) stability model. Moreover, Becker and Leon (1988) stated that successful new hybrids must show good performance for yield and other essential agronomic traits and their superiority should be reliable over a wide range of environmental conditions.

Table 5: Estimates of stability and adaptability parameters of seed yield of 11 sunflower hybrids evaluated in five environments

\begin{tabular}{lcccccccc}
\hline \multirow{2}{*}{ Hybrids } & \multicolumn{9}{c}{ Environments } & & \multicolumn{2}{c}{ Regression $\begin{array}{c}\text { Deviationfrom } \\
\text { regression }\end{array}$} \\
\cline { 2 - 6 } Coefficient & Sennar & $\begin{array}{c}\text { Wad } \\
\text { Medani }\end{array}$ & Rahad & $\begin{array}{c}\text { New } \\
\text { Halfa }\end{array}$ & Suki & & Mean & \\
\hline$(\mathrm{G})$ & $(\mathrm{E} 1)$ & $(\mathrm{E} 2)$ & $(\mathrm{E} 3)$ & $(\mathrm{E} 4)$ & $(\mathrm{E} 5)$ & $\left(\mathrm{x}_{\mathrm{i}}\right)$ & $\left(\mathrm{b}_{\mathrm{i}}\right)$ & $\left(\mathrm{S}^{2}{ }_{\mathrm{d}}\right)$ \\
\hline SFH 32 & 1044 & 1307 & 967 & 2540 & 2530 & 1677 & 1.38 & -3.95 \\
SFH 36 & 1041 & 1432 & 1008 & 2247 & 1673 & 1480 & 0.87 & 11.49 \\
SFH 37 & 1062 & 1372 & 816 & 2396 & 2137 & 1556 & 1.20 & -12.53 \\
SFH 310 & 1451 & 1859 & 1399 & 2432 & 2223 & 1872 & 0.79 & -10.26 \\
SFH 313 & 1369 & 1633 & 1426 & 2569 & 2585 & 1916 & 1.06 & -6.92 \\
SFH 314 & 1087 & 957 & 1210 & 2353 & 2343 & 1590 & 1.15 & 59.10 \\
SFH 341 & 1538 & 1957 & 888 & 2575 & 2279 & 1847 & 1.05 & 86.78 \\
SFH 345 & 1120 & 1238 & 1138 & 2385 & 2370 & 1650 & 1.15 & 1.44 \\
SFH 302 & 1110 & 1405 & 1392 & 2286 & 2015 & 1641 & 0.83 & -0.39 \\
SFH 325 & 1050 & 1566 & 1250 & 2144 & 1796 & 1561 & 0.72 & 5.21 \\
Hysun-33 & 1535 & 1533 & 1361 & 2501 & 2065 & 1798 & 0.81 & -1.87 \\
\hline Env. Mean & 1218 & 1478 & 1168 & 2402 & 2183 & 1690 & 1.00 & \\
Env. Index & 471.46 & 212.13 & 521.67 & 712.33 & 492.93 & & & \\
\hline
\end{tabular}

The average seed and oil yields performances of individual hybrids along with $\mathrm{b}_{\mathrm{i}}$ and $\mathrm{S}^{2}{ }_{\mathrm{di}}$ are presented in Tables 5 and 6 . From the environmental means it was observed that E4 (New Halfa) had the highest means of seed yield $\left(2,402 \mathrm{~kg} \mathrm{ha}^{-1}\right.$ ) and oil yield (1,077.87 $\left.\mathrm{kg} \mathrm{ha}^{-1}\right)$, while E3 (Rahad) had the lowest values for both seed and oil yields (1,168 and $476.57 \mathrm{~kg} \mathrm{ha}^{-1}$, respectively). This indicated that New Halfa had the most favorable environment and that the majority of hybrids had the capacity to exploit that environment to produce the highest seed and oil yields. Across the environments, three local hybrids, SFH313, SFH310 and SFH341, gave the highest seed yields and out-yielded the introduced hybrid Hysun-33. The three 
hybrids also had the highest oil yields compared to the grand mean, while two of them (SFH313 and SFH310) out-yielded Hysun-33 in terms of oil yield (Table 6).

Table 6: Estimates of stability and adaptability parameters of oil yield of 11 sunflower hybrids evaluated in five environments

\begin{tabular}{lcccccccc}
\hline \multirow{2}{*}{ Hybrids } & \multicolumn{9}{c}{ Environments } & & \multirow{2}{*}{$\begin{array}{c}\text { Regression } \\
\text { coefficient }\end{array}$} & $\begin{array}{c}\text { Deviation from } \\
\text { regression }\end{array}$ \\
\cline { 2 - 6 } & Sennar & $\begin{array}{c}\text { Wad } \\
\text { Medani }\end{array}$ & Rahad & $\begin{array}{c}\text { New } \\
\text { Halfa }\end{array}$ & Suki & & & \\
\hline (G) & $(\mathrm{E} 1)$ & $(\mathrm{E} 2)$ & $(\mathrm{E} 3)$ & $(\mathrm{E} 4)$ & $(\mathrm{E} 5)$ & $\left(\overline{\mathrm{x}}_{\mathrm{i}}\right)$ & $\left(\mathrm{b}_{\mathrm{i}}\right)$ & $\left(\mathrm{S}^{2}{ }_{\mathrm{di}}\right)$ \\
\hline SFH 32 & 417.60 & 522.93 & 367.46 & 1092.34 & 961.27 & 672.32 & 1.21 & 0.23 \\
SFH 36 & 424.80 & 466.59 & 318.37 & 1150.24 & 918.77 & 655.7 & 0.87 & 2.84 \\
SFH 37 & 458.04 & 529.96 & 363.00 & 1011.00 & 669.33 & 606.27 & 1.31 & 0.32 \\
SFH 310 & 580.53 & 743.60 & 559.47 & 1094.25 & 978.12 & 791.19 & 0.85 & 0.80 \\
SFH 313 & 602.21 & 653.20 & 584.80 & 1233.38 & 1085.70 & 831.84 & 1.05 & 0.06 \\
SFH 314 & 412.93 & 363.53 & 520.44 & 941.33 & 1054.50 & 658.55 & 1.11 & 7.13 \\
SFH 341 & 615.33 & 822.08 & 355.20 & 1107.11 & 979.83 & 775.91 & 0.97 & 7.44 \\
SFH 345 & 448.00 & 445.68 & 477.82 & 1097.25 & 1019.10 & 697.57 & 1.18 & 1.50 \\
SFH 302 & 466.20 & 519.85 & 584.64 & 1028.70 & 866.59 & 693.20 & 0.86 & 1.41 \\
SFH 325 & 430.50 & 548.22 & 512.36 & 900.62 & 862.08 & 650.76 & 0.77 & 0.85 \\
Hysun-33 & 690.90 & 613.07 & 598.69 & 1200.48 & 825.87 & 785.80 & 0.83 & 4.07 \\
\hline Env. Mean & 504.28 & 566.25 & 476.57 & 1077.87 & 929.20 & 710.80 & 1.00 & \\
Env. Index & 929.2 & 0.11 & 476.60 & 566.20 & 504.30 & & & \\
\hline
\end{tabular}

It has been emphasized that both linear $\left(b_{i}\right)$ and non-linear $\left(\mathrm{S}^{2}{ }_{\mathrm{di}}\right)$ components of $\mathrm{G} \times \mathrm{E}$ interactions are necessary for judging the stability of a hybrid. A regression coefficient $\left(b_{i}\right)$ approximating 1.0 coupled with an $\mathrm{S}^{2}$ di of zero indicates average stability (Eberhart and Russell, 1966). Regression values above 1.0 describe genotypes with higher sensitivity to environmental changes (below average stability) and greater specificity of adaptability to high yielding environments. A regression coefficient below 1.0 provides a measurement of greater resistance to environmental change (above average stability) and thus increases the specificity of adaptability to low yielding environments (Wachira et al., 2002). Also, Zubair et al. (2002) suggested that if the regression coefficients of genotypes are not significantly different from 1.0 the stability of these genotypes should be judged upon the other two parameters, i.e. average mean $(\overline{\mathrm{x}})$ and deviation from regression $\left(\mathrm{S}^{2}{ }_{\mathrm{di}}\right)$.

In the present study, the regression coefficients for seed yield ranged from 0.72 to 1.38 and those for oil yield from 0.77 to 1.31 (Tables 5 and 6 , respectively). These large variations in regression coefficients $\left(b_{i}\right.$ values) give the breeder an advantage to select hybrids for both adverse and favorable environments. Therefore, the resultant regression coefficient $\left(b_{i}\right)$ and deviation from regression $\left(\mathrm{S}^{2}{ }_{\mathrm{di}}\right)$ and mean yield for each hybrid are parameters for estimating the stability of yield over the environments. SFH313, SFH310 and SFH341 gave the highest seed yields over the grand mean with respective regression coefficients of $1.06,0.79$ and 1.05 that were not significantly different from regression (Table 5). Thus, these three 
local hybrids proved to be stable for seed yield, adapted to a wide range of environments, and suitable for general cultivation. Yield and stability of Hysun-33 improved only under optimal growing conditions. In contrast, SFH37 and SFH32 are expected to give good seed yields under favorable environmental conditions due to their greater values of regression coefficient $\left(b_{i}>1.0\right)$, namely 1.38 and 1.20 , respectively.

Regarding oil yield and the three stability parameters for the individual hybrid, SFH313, SFH310, Hysun-33 and SFH341 gave the highest oil yields of 831.84, $791.19,785.80$ and $775.91 \mathrm{~kg} \mathrm{ha}^{-1}$ over the grand mean of oil yield with respective regression coefficients of $1.05,0.85,0.97$ and 0.83 that were not significantly different from regression (Table 6). The hybrids SFH310 and SFH313 had above average oil yields, regression coefficient approximately close to one, and low deviation from regression, indicating wide adaptation and stability for oil yield across the tested environments. Also, Hysun-33 and SFH341 had above average oil yields and regression coefficients close to one, but they had high values of $\mathrm{S}^{2}{ }_{\mathrm{di}}$, showing sensitivity to environmental changes. The rest of the hybrids under study had average oil yields below the grand mean. Therefore, the need to improve the oil content in the hybrid seeds in developing sunflower hybrid oil types is crucial, because oil yield depends on the oil content of the seeds and seed yield of the hybrids.

\section{CONCLUSION}

Consistent high mean seed and oil yields demonstrated by the local sunflower hybrids SFH 310, SFH 313 and SFH 341 and their adaptability and stability make them suitable for cultivation over a wide range of environments. At the same time, the yield and stability of the introduced hybrid Hysun-33 improved only under optimal growing conditions. Also, based on the availability of parental lines (A, B and Rlines), the three local hybrids were released last June for commercial production under irrigated conditions in the central clay plains of Sudan. Therefore, local seed production will be a safeguard for sunflower production against foreign political constraints concerning seed importation.

\section{ACKNOWLEDGEMENTS}

The author is thankful for the financial support of the Agricultural Research Corporation (ARC), Wad Medani, Sudan. The follow-up of the Director General of ARC, Prof. Azhari A. Hamada, is highly acknowledged.

Thanks are also due to the staff of the Sennar, Suki, Rahad and New Halfa Research Stations for their unlimited help in the collection of the data. 


\section{REFERENCES}

Adam, N.E.M. and Osman, H.G., 1989. Performance of some open-pollinated sunflower varieties at the Blue Nile under rain and supplementary irrigation. Paper submitted to Variety Release Committee. Khartoum, Sudan.

Becker, H.C. and Leon, J., 1988. Stability Analysis in Plant Breeding. Plant Breeding 101: 1-23.

Eberhart, S.A. and Russell, W.I., 1966. Stability parameters for comparing varieties. Crop Science 6: 30-40.

Finlay, K.W. and Wilkinson, G.N., 1963. The analysis of adaptation in plant-breeding programme. Aust. J. Agric. Res. 14: 742-754.

El Ahamdi, A.B., 2003. A proposal for the release of three sunflower hybrids. Paper presented to the Variety Release Committee. Khartoum, Sudan.

Gomez, K.A. and Gomez, A.A., 1984. Statical procedures in Agricultural Research. $2^{\text {nd }}$ ed. John Wiley and Sons Inc. New York.

Kinman, M.L., 1970. New developments in the USDA and state experiment station sunflower breeding program. Proc. $4^{\text {th }}$ Int. Sunflower Conf. Memphis, Tennessee, pp. 181-183.

Leclercq, P., 1966. An utilizable mail sterile line for the production of hybrid sunflower. Ann. Amelior. Planta 76: 135-139.

Miller, J.F., 1999. Heterosis: Feeding People and Protecting Natural Resources. In: Coors, J.G. and Pandey, S. (Eds), The Genetics and Exploitation of Heterosis in Crops. ASA, CSS, SSS, Madison, WI, USA, pp. 19-29.

Nour, A.M., Mohamed, M.Y., and Ahmed, O.M., 2005. A proposal for the release of new sunflower hybrids for rainfed and irrigated conditions of the Sudan. A paper presented to the Variety Release Committee. Khartoum, Sudan.

Škorić, D., 1992. Achievement and future direction of sunflower breeding. Field Crop Research 30: 231-270.

Wachira, F., Wilson, N.G., Omolo, J. and Mamati, G., 2002. Genotype $\times$ environment interactions for tea yields. Euphytica 127: 289-296.

Zubair, M., Anwar, M., Haqqani, A.M. and Zahid, M.A., 2002. Genotype-environment interaction for grain yield in mash (Vigna mungo L. Happer). Asian J. Pl. Sci. 1(2): 128-129. 
